\title{
A PROPOSTA DE REFORMA DO ENSINO MÉDIO NO ESTADO DA BAHIA NOS ANOS 2000: O CONTEXTO DE DEFINIÇÃO DE TEXTOS
}

\author{
Benedito G. Eugênio ${ }^{1}$ \\ Universidade Estadual do Sudoeste da Bahia.
}

\begin{abstract}
Resumo: $\mathrm{O}$ texto apresenta os resultados de uma investigação sobre a reforma curricular implantada para o ensino médio no Estado da Bahia na gestão do 2003-2006. Valendo do modelo do ciclo de políticas proposto por Ball, analisamos o contexto da definição de textos da reforma do ensino médio. Os dados foram construídos por meio de uma pesquisa documental e exploratória em uma escola pública. Para isso, utilizamos análise de documentos, observações de aulas e entrevistas. Concluímos apontando alguns elementos que caracterizam a política estudada.
\end{abstract}

Palavras-chave: politica curricular, ensino médio, reforma.

\section{LA PROPUESTA DE REFORMA DE LA EDUCACIÓN SECUNDARIA EN EL ESTADO DE LA BAHIA EM LOS AÑOS 2000: EL CONTEXTO DE DEFINICIÓN DE TEXTOS}

Resumen: El artículo presenta los resultados de una investigación sobre la reforma curricular implementado para la educación secundaria en el estado de Bahía, en la gestión 2003-2006. Basándose en el modelo del ciclo de política propuesta por Ball, analizamos el contexto de la definición de los textos de la reforma de la educación secundaria. Los datos fueron construidos a través de una investigación documental y exploratoria en una escuela pública. Para ello, se utilizó el análisis de documentos, observaciones de clase y entrevistas. Llegamos a la conclusión de que hay algunos elementos que caracterizan la política estudiada.

Palavras clave: política curricular, educación secundaria, reforma.

\section{THE PROPOSAL OF EDUCATION REFORM SECUNDARY IN THE BAHIA STATE IN YEARS 2000: THE CONTEXT SETTING TEXTS}

\begin{abstract}
This paper presents research results about the curriculum reform implanted for secondary education in the state of Bahia by the administration 2003-2006. Drawing upon the policy cycle model proposed by Ball, we analyzed the context of text definition of the high school reform. Data were built through documentary and exploratory research in a public school. We used document analysis, class observations and interviews. We conclude that there are some elements that characterize the policy studied.
\end{abstract}

Keywords: policy curriculum, high school, reform.

${ }^{1}$ Universidade Estadual do Sudoeste da Bahia- Campus de Vitória da Conquista. Doutor em Educação (UNICAMP). Professor Adjunto da Universidade Estadual do Sudoeste da Bahia- Campus de Vitória da Conquista. Programa de Pós-Graduação em Relações Étnicas e Contemporaneidade. E-mail: beneditoeugenio@bol.com.br 


\section{Introdução}

Os anos 1990, auge da reforma neoliberal do Estado brasileiro, tem como características, no caso do campo educacional, modificações no currículo (estabelecimento de diretrizes curriculares para todos os níveis e modalidades, produção de documentos curriculares), na formação de professores e na gestão educacional. Todas essas reformas fizeram parte do processo de redefinição do papel do Estado, utilizando, para isso, a justificativa de que com isso elevaríamos os padrões de qualidade e de eficiência da educação, conforme nos aponta Peroni (2003).

No caso do currículo, desde a publicação dos Parâmetros Curriculares Nacionais (PCN), em 1995, que instituiu os princípios da reforma curricular para a Educação Básica no Brasil, diversos estudos pontuaram como esses documentos propuseram princípios para um currículo nacional e suas consequências para a educação nacional (Jacomeli, 2007; Teixeira, 2008, 2011; Santos, 2015).

A política curricular brasileira implementada a partir dos anos 1990, produziu uma série de documentos (diretrizes, orientações curriculares, PCN), assim como cursos para ensinar aos docentes o processo de transposição didática da política, a exemplo do Parâmetros em Ação. Além disso, o Programa Nacional do Livro Didático (PNLD) passou a adotar, como critério para a avaliação dos livros submetidos ao Programa, estarem de acordo com os PCN. Todos esses elementos evidenciam o quanto foram produtivos o discurso e as práticas para a implementação de um currículo nacional.

Tomando como base a reforma nacional, diversos Estados e municípios também propuseram alterações curriculares. No Estado da Bahia, a reforma incidiu sobre o ensino médio, por meio do Projeto Bahia, na gestão 2003-2006.

A reforma foi efetivada por meio das Orientações Curriculares Estaduais e seus princípios foram registrados em três volumes. Para efetuar a análise aqui apresentada, apoiamo-nos teoricamente na perspectiva do ciclo de política proposta por Stephen Ball, especificamente o contexto da produção de textos, conforme especificado por Mainardes (2007).

Ball propõe um modelo heurístico para a análise das políticas educacionais, a abordagem do ciclo de políticas, constituída por contextos interligados de uma forma não-hierárquica e que permite “... a análise crítica da trajetória de programas e políticas educacionais desde sua formulação inicial até a sua implementação no contexto da prática e seus efeitos." (Mainardes, 2006, p. 48).

O modelo heurístico proposto por Ball e colaboradores vem sendo empregado, no Brasil, principalmente a partir de 2004, em diversos estudos acadêmicos desenvolvidos, por exemplo, na Universidade Estadual de Campinas, Universidade Estadual do Rio de Janeiro, Universidade Federal Fluminense, Universidade Federal de Pernambuco, PUC-Rio, PUC/SP. Mais recentemente, o periódico Arquivos Analíticos de Políticas Educativas, em seu volume 6/2016, dedicou uma seção à teoria de Ball, evidenciando a potencialidade de seus conceitos para o estudo da política educativa. 
De acordo com Ball (1994), a política deve ser compreendida como processo e resultado. Os textos representam a política, mas não são a política, tendo em vista que eles são lidos, interpretados e reinterpretados e, nesse processo, novos significados lhes são atribuídos.

Também, segundo este autor, “... a reforma não muda apenas o que fazemos. Ela também procura mudar aquilo que somos, aquilo que poderíamos vir a ser. (2005, p. 546), o que possibilita compreender que "Novos papéis e subjetividades são produzidos à medida que os professores são transformados em produtores/fornecedores, empresários da educação e administradores, e ficam sujeitos à avaliação, análises periódicas e a comparações de desempenho.” (Ball, 2005, p. 546).

O texto da política que chega às escolas em forma de diretrizes, normas, parâmetros, tem uma história e os destinatários desses textos também têm uma história, portanto, não são leitores ingênuos nem passivos, pois interpretam esses textos de diferente forma. Os textos políticos são o resultado de uma série de negociações, de múltiplas influências e intenções. Em seu processo de construção, algumas vozes são legitimadas e ouvidas.

Mainardes (2007, p.38) “... a análise de documentos de políticas não é algo simples, demanda pesquisadores que sejam capazes de identificar ideologias, interesses, conceitos empregados, embates envolvidos no processo, as vozes presentes e ausentes, entre outros aspectos". Partindo desse entendimento, o Estado é apenas um dos teorizadores e produtor dos textos curriculares, sendo estes “... documentos de trabalho que simbolizam o discurso oficial do Estado que agrega interesses diversos e alianças elaboradas a diversos níveis de ação.” (Pacheco, 2000, p.15).

Para além do discurso do Estado, há uma série de outros que também legitimam a política curricular e que são produzidos no contexto das diferentes práticas curriculares, como as escolas, as editoras, as comunidades epistêmicas. Essas últimas, segundo Lopes (2006, p.41), produzem instrumentos de homogeneização, “... na medida em que fazem circular diagnósticos sobre a situação educacional e organizam modelos de solução para os problemas identificados, valorizando seu próprio conhecimento como fonte dessas soluções".

Neste artigo, analisamos a reforma curricular para o ensino médio implementada no Estado da Bahia, tomando como modelo heurístico a abordagem do ciclo de políticas proposto por Ball. Trabalhamos tão somente com o contexto da produção de textos, contexto que engloba a produção de diversos materiais, tais como documentos, pareceres, discursos oficiais, intervenção da mídia, vídeos, comentários formais ou informais sobre os textos oficiais. Ressaltamos que esses textos não são necessariamente coerentes e claros, podendo até mesmo serem contraditórios, pois são o resultado de acordos e disputas pelos grupos que competem para controlar as representações da política. 


\section{Método}

Este artigo apresenta os resultados de uma pesquisa etnográfica realizada em uma escola pública de Vitória da Conquista - Bahia - Brasil e que objetivou compreender como se efetiva o processo de recontextualização de uma política curricular no espaço cotidiano da escola. Para isso, utilizamos análise de documentos, observações de aulas e entrevistas. Para a construção deste artigo, contamos, além dos documentos produzidos pelo Estado, isto é, pelo campo recontextualizador oficial (Bernstein, 1996), com entrevistas realizadas com docentes que representaram a Região do sudoeste baiano no processo de discussão/produção inicial dos documentos.

Evangelista (s. d., p. 09) aponta que “... documentos são produtos de informações selecionadas, de avaliações, de análises, de tendências, de recomendações, de proposições. Expressam e resultam de uma combinação de intencionalidades, valores e discursos. São constituídos pelo e constituintes do momento histórico”.

Para Shiroma, Campos e Garcia (2005), na análise de documentos de políticas é fundamental atentar para os vocábulos e os sentidos a eles atribuídos, pois palavras importam e fazem diferença.

Usar os textos políticos como fonte de investigação é uma das formas de investigação em política educacional, e é recomendável não apenas pela sua acessibilidade, mas porque uma leitura atenta dos textos políticos ajuda a gerar respostas críticas, informadas e independentes face às políticas. Ler e interpretar textos podem ser actos de envolvimento na política, quer para o investigador, quer para aqueles com quem trabalha. (Ozga, 2000, p. 192).

Mainardes (2009), em texto que procura apontar a relevância das abordagens metodológicas para o estudo das políticas educacionais, aponta que este é um campo ainda em consolidação em nosso país. Segundo o autor, o estudo de políticas educacionais no Brasil pode ser organizado em dois grupos: os estudos de natureza teórica sobre formulação de políticas e análise e avaliação de políticas educacionais específicas. Ambos os tipos de análise são relevantes. No entanto, segundo Mainardes (2009), é preciso articular as duas perspectivas, isto é, o macro e o micro.

No caso da política aqui apresentada, valemo-nos da contribuição de um desses referenciais, a abordagem do ciclo de políticas proposto por Stephen Ball. Discutimos especificamente o contexto da produção de textos da reforma curricular para o ensino médio baiano, implantada no período mencionado.

\section{Resultados e discussão}

Considerando os objetivos da pesquisa, os resultados sistematizam análises documentais e percepções de profissionais em atuação no período da reforma educacional. 


\section{Algumas considerações sobre o Projeto Bahia}

Tomando como base a reforma do ensino médio desenvolvida pelo Governo Federal, o Estado da Bahia também elaborou diretrizes curriculares para este nível de escolarização. A elaboração das Orientações Curriculares fez parte de um projeto maior, denominado Projeto de Educação do Estado da Bahia, configurado em um conjunto de documentos divulgados pelas Secretarias de Educação e de Planejamento do Estado (Bahia 2004, 2005 e 2006), além do relatório do Banco Mundial (2003).

O Projeto Bahia constitui-se de acordos de financiamento resultantes da negociação da Secretaria Estadual de Educação com o Banco Mundial, no final dos anos 1990. Sua elaboração previu o desenvolvimento dos acordos em duas fases: 2001 a 2003 (fase I) e 2003 a 2006 (fase II). O Acordo de Empréstimo número 4592-BR foi assinado com o Banco Mundial em 12 de fevereiro de 2001.

Seu objetivo era promover a melhoria do ensino por intermédio do fortalecimento das escolas e das instituições responsáveis por elas, em consonância com uma nova realidade e tendências decorrentes da implantação do Fundo de Manutenção e Desenvolvimento do Ensino Fundamental e de Valorização do Magistério - FUNDEF; do processo de municipalização das escolas fundamentais estaduais; e da prioridade dada ao fortalecimento da gestão educacional nos níveis estadual, regional e da própria escola.

De acordo com Machado (2007, p. 86), o acordo do Estado da Bahia com o Banco Mundial foi de R $\$ 216$ milhões. Ainda segundo a mesma autora, "Para cada um dos acordos firmados, o Banco adota referenciais muito precisos para a definição de metas a serem alcançadas e para o estabelecimento de parâmetros para a liberação de recursos." Isso, no entanto, não significa que no contexto das práticas e dos resultados, não haja resistências, continuidades e descontinuidades, seja por parte dos técnicos da Secretaria de Educação, seja por parte dos docentes.

O gerenciamento do Projeto ficou sob a responsabilidade da Secretaria Estadual de Educação. Em 1999, com a reforma da Secretaria, criou-se a Coordenação de Projetos Educacionais - COPE, unidade gestora responsável pelos projetos financiados com recursos externos.

A estrutura gerencial do Projeto ficou assim constituída: 
Figura 1: Estrutura gerencial do Projeto de Educação Bahia

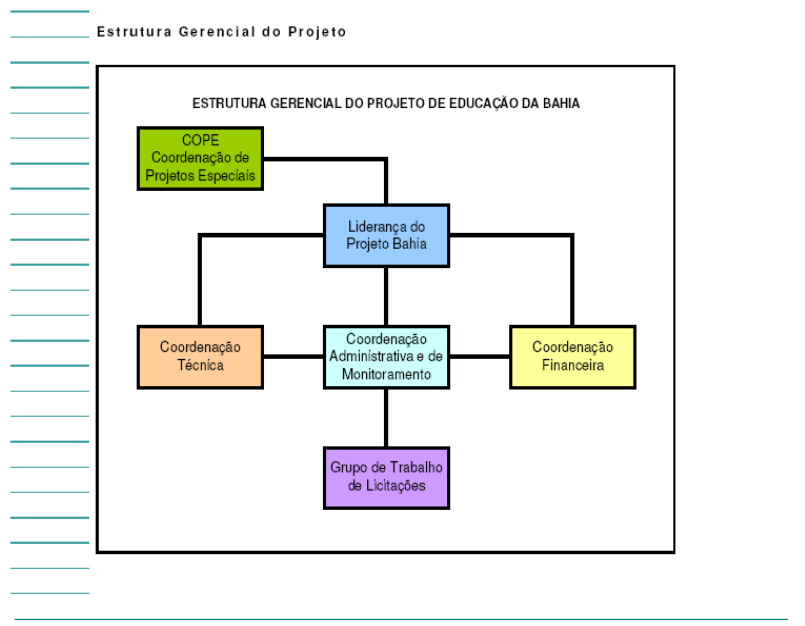

Fonte: Bahia (2004)

As ações do Projeto estruturaram-se em três componentes e estes, por sua vez, subdividiam-se em subcomponentes, conforme descritos na sequência (Bahia, 2004):

a) Componente 1: Melhoria da qualidade do ensino fundamental e médio.

Subcomponentes: melhoria da qualidade do ensino fundamental; melhoria da qualidade do ensino médio; melhoria da qualidade do ensino em comunidades indígenas.

b) Componente 2: Ampliação do acesso ao ensino médio.

Subcomponente: ampliação da rede estadual de ensino médio.

c) Componente 3: Fortalecimento da gestão educacional.

Subcomponentes: autonomia financeira plena para o ensino médio; avaliação da rede pública; avaliação e monitoramento do projeto; certificação ocupacional de profissionais da educação.

Para cada um dos componentes estavam previstas a quantidade de escolas, alunos e municípios a serem atendidos. Previu-se também o valor a ser empregado entre os anos de 2003 a 2006. O Governo do Estado também destacou quais as premissas importantes para a elaboração do Projeto. Para o ensino médio foram: continuidade da política de prioridade da educação do Estado; política efetiva de atração de recursos qualificados para o magistério.

Em 1998, foi propôs um modelo de gestão gerencialista na educação do Estado e, devido ao elevado índice de reprovação, foi desenvolvido um projeto denominado Escola nas Férias, com aulas durante o mês de janeiro, cujo objetivo era a aprovação de todos os alunos então reprovados, principalmente os do ensino médio. Hoje é possível 
apreender que tal proposta, na verdade, era tão somente o cumprimento das metas previstas nos acordos internacionais assinados pelo Estado $^{2}$, conforme pode ser verificado no trabalho de Machado (2007, p. 189) acerca do processo de negociação do Banco Mundial com o governo da Bahia. De acordo com a autora:

O processo de negociação do Projeto Bahia ocorreu entre os anos de 1998 até junho de 2007 e, desde os seus primórdios, envolveu uma relação direta do governo do Estado da Bahia com técnicos do Banco Mundial, contando com uma ação coordenada de representantes da Secretaria Estadual de Educação, Secretaria de Planejamento, consultores externos e uma equipe técnica contratada para tarefas específicas no âmbito do projeto.

Em 2001, foi implantado o Projeto de Aceleração do Ensino Médio, com a proposta de conclusão dessa etapa em dois anos, no período noturno. A organização curricular estava organizada de forma que no primeiro ano os estudantes tinham aulas das disciplinas de linguagem e ciências humanas e no segundo, exatas e biológicas. Esta, aliás, é a organização que persiste até hoje, o que nos mostra que os meandros da política ultrapassam os limites da administração de determinado partido político.

Cada componente anteriormente abordado contou também com ações e indicadores de verificação do seu alcance, todos baseados na quantidade de alunos, escolas e municípios atendidos. Previu-se também a realização de provas a cada dois anos para avaliar os resultados do Projeto no que tange à qualidade do ensino.

A justificativa para a elaboração das Orientações Curriculares Estaduais, composta por três volumes - um para cada uma das áreas propostas pelo MEC - foi a de que seguindo a reforma nacional, os Estados federados também teriam o direito de adotar propostas curriculares. De acordo com a parte geral do referido documento, sua elaboração "Constitui-se um processo de construção coletiva, um grande mutirão, que mobilizou 1174 professores de 33 Diretorias Regionais de Educação, técnicos da Secretaria de Educação, especialistas das três áreas do conhecimento que estruturam o currículo do Ensino Médio, agregando 82 unidades escolares da Rede Estadual.” (Bahia, 2005, p.13).

Nos diálogos com parte desses profissionais, inclusive das escolas situadas entre as que participaram do processo, não souberam informar, sobre os encontros realizados

2 Desde os anos 1970 temos projetos sociais desenvolvidos com apoio financeiro de organismos internacionais, particularmente o Banco Mundial, no Estado da Bahia. Dentre esses projetos destacam-se o EDURURAL e o Pólo Nordeste (para construção de escolas). Nesse período (1995-1998) estava em fase de execução o Projeto Nordeste. Para maiores detalhes, ver o trabalho de Machado (2007). 
para a elaboração das orientações curriculares. Estas conversas, contudo, foram importantes para a identificação de dois professores que representaram a DIREC-20 na discussão do documento em Salvador, no ano de 2004. Os dois docentes, identificados por P1 e P2, integram o quadro de profissionais efetivos da rede pública estadual baiana, sendo o primeiro de História e o outro, Matemática.

Segundo um dos docentes, assim ocorreu o processo de discussão das Orientações Curriculares:

A primeira coisa que eu acho importante é a manobra que tentaram fazer no processo de construção dessas Orientações. De início, teve uma reunião no Colégio Modelo com representantes da região e, nesse espaço cada sala, que era por área, tinha um técnico da Secretaria que tentava indicar quem seria o representante por disciplina. Na sala que eu estava, comecei a questionar uma série de situações que a gente vivenciava e a turma acabou me indicando para ser representante, mas a técnica da Secretaria fez de tudo para eu não ir ao encontro que iria acontecer em Salvador. Na verdade, Conquista sempre ficou à margem de qualquer construção, ora por conta da disputa política, porque Conquista se enquadra como um espaço da esquerda frente ao carlismo, contrapondo-se sempre ao carlismo. Ao longo do tempo sempre se manteve essa disputa. Por outro lado, esse é um processo interno de categoria; Conquista nunca se dobrou ao sindicato (APLB) e essa construção eu me lembro que teve um processo anterior às Orientações Curriculares, formado por audiências públicas. Nossa região foi a única que não fez as audiências, que deveria envolver a sociedade civil, os sindicatos, professores e Conquista ficou de fora exatamente pela posição política estabelecida frente ao sindicato, sempre em oposição a essa direção extremamente complicada que nós temos. A própria APLB foi quem acabou destruindo a participação de Conquista nesse processo. (P1)

As diretrizes curriculares estaduais: expressão do contexto de produção/definição de textos

A leitura dos documentos da reforma estadual possibilita apontar algumas marcas da reforma nacional para o ensino médio: a organização curricular por competências e habilidades; a proposição de temas estruturadores no documento relativo à área de Ciências da Natureza, Matemática e suas Tecnologias, item que 
também está presente nas Orientações Curriculares para o Ensino Médio (Brasil, 2006). Estas assim definem os temas estruturadores: “... têm a função de ajudar o professor a organizar suas ações pedagógicas, configurando-se como meios para atingir os objetivos do projeto pedagógico da escola, e não como objetivos em si.” (Brasil, 2006, p.21). Já as Orientações Curriculares Estaduais trazem explicitamente a referência ao documento nacional: “... a extensa lista de Física pode ser apresentada na forma de temas estruturadores, como sugeridos nos $\mathrm{PCN}+$, entendendo que essa não é a única maneira de organização dos conteúdos." (Bahia, 2005, p. 93).

Os temas estruturadores presentes nas disciplinas que compõem a área de Ciências da Natureza, Matemática e suas Tecnologias no documento nacional são exatamente os mesmos do estadual, embora a publicação destes documentos seja de anos diferentes (Brasil, 2006; Bahia, 2005).

Como em qualquer processo de reforma curricular, as relações de poder e a luta para definir as normas que orientariam a organização curricular também se fizeram presentes no processo de produção das Orientações Curriculares Estaduais, conforme relatam os docentes a seguir:

Esse processo foi extremamente irreal, pois o tempo todo a Secretaria de Educação estava conduzindo o processo, deu para perceber isso. As próprias pessoas que estavam lá comungavam com as diretrizes ou as propostas de indicação da Secretaria. É claro que por conta do corporativismo da categoria, algumas questões eram apresentadas, mas logo eram abarcadas; apenas 3 ou 4 se contrapunham ao que estava acontecendo. $\mathrm{O}$ processo de formação do grupo para apresentar foi extremamente conturbado, todo manipulado pela própria Secretaria. Os técnicos são bastante... eu não diria que eles são habilidosos, mas contam muito com a desinformação do próprio professor. Como a discussão era fazer uma construção coletiva, eles tendenciavam, mas não poderiam determinar. Então houve o confronto. (P1)

Em Salvador eles abriam a plenária para discutir os temas que eram colocados. A gente colocava nossa opinião, o que havia sido discutido, mas a mesa votava absolutamente tudo. Tudo que era colocado, o pessoal da mesa falava que ia servir como apoio para a organização do documento. Depois era aprovado nas assembleias; o pessoal votava e encaminhava o processo para as 
colocações que eles faziam. A incorporação de tudo aquilo que a gente falou no texto, eu não saberia lhe dizer se houve ou não. (P2)

Pelos depoimentos, é possível perceber que P1 apresenta com maiores detalhes do que P2 o processo que culminou com a aprovação das Orientações Curriculares. $\mathrm{O}$ interesse do Governo Estadual em aprovar as Orientações deve-se, entre outros, à necessidade de cumprimento do acordo assinado com o Banco Mundial por meio do Projeto Bahia, o que demandaria toda uma estratégia de trabalho para sua elaboração e posterior aprovação.

Com relação ao documento curricular produzido ao final das discussões, os docentes assim se posicionam:

As Orientações Curriculares da Bahia formam um documento que não chegou ainda às mãos do professor, quer dizer, algumas escolas receberam, mas ainda não houve uma discussão, uma leitura para que o professor compreenda o que é o documento. Aqui na escola mesmo a gente recebeu, mas ainda não fez a devida leitura. Na parte de História, por exemplo, que é da minha área, eu li rapidamente. É um documento bonito, organizado. (P2)

Eu me lembro que teve uma discussão extremamente complicada para a nossa categoria que foi da atividade complementar - AC, porque em todas as audiências que ocorreram nas regionais os professores, junto com a sociedade civil que participou, eles reconheceram a necessidade de ampliação da carga horária do professor para estudo, planejamento, etc. No entanto, a Secretaria colocou isso como um tópico muito solto e tentou construir a imagem de que as atividades complementares não funcionam nas escolas. A Secretaria utilizou até algumas falas de professores para tentar mostrar que não havia necessidade das $\mathrm{AC}$; o professor teria que ter $20 \mathrm{~h}$ em sala de aula. Isso gerou uma polêmica muito grande e inclusive nós já estávamos preparados para ceder neste ponto; deu para verificar que na construção anterior, que teve um questionário enviado para as escolas e os diretores daquela época, foi feito questão de passar nas AC, tentando fazer uma avaliação sobre o processo. (P1)

Novamente é possível perceber os embates internos ocorridos no processo de construção do texto da política e verificar que as Orientações Curriculares não chegaram ao conhecimento de boa parte do professorado. Levantamos a hipótese que talvez uma 
das razões para isso seja o fato do documento ter sido produzido no final do Governo (2005) e, como no ano seguinte era época do período eleitoral, as Orientações não foram devidamente conhecidas e discutidas. Constatamos que algumas escolas sequer receberam este documento curricular.

Em seu interior, as Orientações Curriculares Estaduais apontam o elevado número de estudantes em distorção idade/série e também os altos índices de evasão e repetência existentes no Estado e que se constituem como entraves à educação de qualidade. Este mesmo ponto apareceu durante a entrevista realizada com o professor P1, que assim relata como se deu a discussão da temática quando da elaboração das Orientações:

Nós temos um problema sério na escola que é a evasão, que envolve uma série de fatores e o que a Secretaria colocava sobre a evasão era tentando encontrar culpados e a pergunta era: qual a responsabilidade do professor na evasão escolar?, mas nunca perguntava sobre o poder público, o Estado, que obrigatoriamente é o promotor dessa educação e até mesmo verificar porque existe essa evasão. A evasão e a repetência foram os dois focos centrais desse processo; o tempo todo foi falado desses problemas, mas sem destacar as causas verdadeiras disso, sempre se remetendo ao professor como responsável por isso. É preciso lembrar que não existe coordenação. O processo de construção das Orientações Curriculares foi extremamente tendencioso, apesar que numa finalização é possível notar alguns avanços. (P1)

A estrutura das Orientações Estaduais está constituída em três volumes: uma parte geral presente em todos eles, em que se informam os fundamentos e perspectivas para o trabalho com o ensino médio e um documento por área: Linguagens, Códigos e suas Tecnologias; Ciências da Natureza, Matemática e suas Tecnologias; Ciências Humanas e suas Tecnologias. Tais orientações fazem parte de um conjunto de medidas que visam à reforma do ensino médio e não apenas uma simples mudança na prática docente.

Reafirmando essa constatação, valemo-nos da contribuição de Popkewitz (1997). Para este autor, reforma e mudança apresentam significados diversos. A reforma faz referência à mobilização dos públicos e às relações de poder na definição do espaço público, enquanto a mudança refere-se ao confronto entre rupturas com o passado e com o que parece estável e 'natural' em nossa vida social. 
Como documento curricular, as Orientações Estaduais convocam as escolas a adotarem um currículo flexível, comprometida com a proposição de situações de aprendizagem diferenciadas, que respeite as diferenças e escute as várias vozes (Bahia, 2005). A elaboração do currículo pelas escolas “... deve partir da constatação de que os jovens e os adolescentes que freqüentam as escolas são pessoas que nas suas práticas sociais cotidianas interagem em processos de comunicação, com a cultura e com a sociedade," (Bahia, 2005, p.36).

No entanto, a participação das unidades escolares no processo de construção do documento curricular é assim descrito pelo P1:

A questão dessa construção é muito de papel. Daqui da escola fomos três professores que participamos, um de cada área. Nós não tivemos tempo hábil para discussão; tínhamos duas semanas para discutir e depois teríamos que ir para Salvador e o documento era muito extenso, envolvia fazer um diagnóstico da educação que você não faz de um dia para outro. Se você perguntar para os professores quais os problemas da educação, ele vai elencar uma série de fatores isolados que, quando agrupados, a gente chega na questão administrativa. Efetivamente nós não pensamos em realizar seminário em Conquista para discutir todas as escolas, para a gente levar uma posição da cidade para a reunião em Salvador. Nós tivemos várias dificuldades do ponto de vista administrativo: a escola que não dispunha de tempo, o cumprimento dos 200 dias letivos, que impossibilitava a reunião dos professores e tudo isso para não permitir que se fizesse um diagnóstico verdadeiro, porque se a gente analisar, não precisa fazer muita coisa para detectar uma série de problemas que tinha anteriormente e continua nesse (governo), eu diria que de forma acentuada, alguns são fáceis de resolver, mas depende de uma ação administrativa. E aí nós temos interesses diversos; vejo que é possível melhorar a escola, no entanto, o pessoal tende a manter do jeito que está porque é melhor para controlar.

A opção por um currículo por áreas justifica-se, de acordo com as Orientações porque “... resulta do entendimento de que essa organização pode facilitar a construção do conhecimento de forma a torná-la mais próxima de sua inteireza, o que descarta um currículo fragmentado.” (Bahia, 2005, p. 37). 
Verificamos que a ideia, expressa no documento, reitera um currículo sem fortes fronteiras disciplinares. Tomando como base a teoria de Bernstein (1996), partimos do pressuposto de que a organização em áreas, aliada à interdisciplinaridade, teria como resultado classificação e enquadramento fracos, por isso, “... assegurar esse entendimento só é possível se a comunidade escolar adotar uma metodologia que legitime os princípios da interdisciplinaridade e da contextualização" (Bahia, 2005, p. $37)$.

Com relação à prática pedagógica, a proposta é que o currículo seja organizado por projetos.

A ideia é de que recursos como esses possam favorecer um processo de aprendizagem vinculado ao mundo de fora da escola, oferecendo uma alternativa para a aproximação entre o conhecimento escolar e as práticas sociais, o que, certamente, possibilitaria uma ampliação da representação da realidade trazida pelo estudante e, ao mesmo tempo, desafiaria o professor para uma atitude de investigação frente ao conhecimento (Bahia, 2005, p. 43).

Argumentamos que as Orientações Estaduais, enquanto documento do campo recontextualizador oficial, vale-se de uma estratégia, aliás, prática comum nos documentos das políticas curriculares ${ }^{3}$ : trazer o discurso de docentes que foram consultados durante sua elaboração. Certamente essa é uma das maneiras encontradas pelo CRO para que os professores não vejam o documento como uma imposição governamental, mas um processo de negociação e diálogo.

Tendo como orientador o trabalho de Bernstein (1996,1998), argumentamos que as Orientações Curriculares Estaduais pretendem a passagem de uma pedagogia visível para uma pedagogia invisível, na medida em que reiteradamente o aluno aparece como o foco do processo de ensino-aprendizagem e que não há um padrão de desempenho externo a ser atingido pelo/as discentes.

\section{Considerações finais}

Neste artigo, apresentamos alguns elementos que caracterizaram a reforma curricular para o ensino médio implementada no estado da Bahia. Para isso, tomamos como base as Orientações Curriculares Estaduais (documento em três volumes e que

3 Na pesquisa que resultou na elaboração de sua tese de doutorado, Edna Abreu Barreto (2008), ao investigar a política curricular implantada pela Escola Cabana no período de 1997-2004, também verifica o recurso ao discurso dos docentes como forma de legitimar o texto político. 
apresenta os principais pontos da reforma) e entrevistas com os dois docentes que representaram a Região Sudoeste do Estado no processo de discussão/produção do documento.

É possível concluir, a partir de uma análise detalhada do Projeto Bahia, que alguns aspectos que demandam maiores considerações, o que não será aqui empreendido por conta do espaço destinado ao texto: ao mesmo tempo em que propõem um currículo flexível, impõem a certificação de professores e atrelam o avanço na carreira ao resultado do exame; propõe um currículo organizado em áreas e prescreve as competências e habilidades a serem trabalhadas e atingidas pelos discentes; para as escolas rurais, a proposta é um currículo mediado pelas tecnologias, numa clara estratégia de pauperização da formação oferecida aos jovens rurais, tendo em vista que há um tutor para mediar as aulas e não professores com formação específica e muitas dessas escolas não apresenta a mínima condição de infraestrutura.

Os elementos aqui elencados levam-nos a pressupor que, conforme afirma Bernstein (1996,1998), como o afrouxamento do enquadramento de uma pedagogia visível aumenta os custos da transmissão e tem implicações na formação docente, o recurso à listagem de competências e a institucionalização de um programa nacional de livros didáticos, que prescrevem os conteúdos, foram estratégias empregadas para a efetivação da política, pois não demandariam maiores investimentos na formação do professor.

Investigações que procurem aprofundar diferentes facetas das políticas educacionais são extremamente necessárias e, para isso, precisamos constituir teórica e metodologicamente o campo e formar investigadores para tal empreitada, conforme pontuam Tello (2015) e Tello e Almeida (2013). Nesse sentido, esta pesquisa se comprometeu com esse processo e analisou a legitimação de uma política e a percepção de docentes que vivenciaram sua elaboração.

\section{Referências}

Bahia. (2006). Plano de implementação do Projeto de Educação da Bahia Fase II. Salvador: Secretaria Estadual de Educação.

Bahia. (2005). Orientações curriculares estaduais. Salvador: Secretaria Estadual da Educação.

Ball, S. (2005). Profissionalismo, gerencialismo e performatividade. Cadernos de Pesquisa, $35,126,539-564$.

Bernstein, B. (1996). Classes, códigos e controle. Petrópolis: Vozes. 
Bernstein, B. (1998). Pedagogía, control simbólico y identidade. Madri: Morata.

Brasil. (1999). Parâmetros Curriculares Nacionais para o Ensino Médio. Brasília: Secretaria de Educação Média e Tecnológica.

Brasil. (2002). PCNEM+. Brasília: Secretaria de Educação Média e Tecnológica.

Brasil. (2006). Orientações Curriculares para o Ensino Médio. Brasília: Secretaria de Educação Básica. Departamento de Políticas de Ensino Médio.

Evangelista, O. (s. d.). Apontamentos para o trabalho com documentos de política educacional. Recuperado em 20 de março de 2015, de http://www.gepeto.ced.ufsc.br

Jacomeli, M. R. (2007). PCNs e temas transversais: análise histórica das políticas educacionais brasileiras. Campinas: Alínea.

Lopes, A. C. (2006). Discurso nas políticas de currículo. Currículo sem fronteiras, 6, 2, 33-52.

Machado, C. T. (2007). O Banco Mundial e a educação no Brasil: uma análise comparativa dos processos de negociação. Tese (Doutorado em Educação). Faculdade de Educação da UFBA, Salvador.

Mainardes, J. (2009). Análise de políticas educacionais: breves considerações teóricometodológicas. Contrapontos, 9, 1, 4-16.

Mainardes, J. (2006). Abordagem do ciclo de políticas: uma contribuição para a análise de políticas educacionais. Educação e Sociedade, 27, 94, 47-69.

Mainardes, J. Reinterpretando os ciclos de aprendizagem. São Paulo: Cortez, 2007.

Ozga, J. (2000). Investigação sobre politicas educacionais: terreno de contestação. Porto: Porto Editora.

Pacheco, J. A. (2000). Políticas curriculares descentralizadas: autonomia ou recentralização? Educação e Sociedade, 21, 73, 139-161.

Peroni, V. (2003). Política educacional e papel do Estado no Brasil dos anos 1990. São Paulo: Xamã.

Popkewitz, T. (1997). Reforma educacional: uma proposta sociológica. Porto Alegre: Artmed.

Santos, R. A. (2015). Os PCN como política unificadora de um currículo nacional: impasses e desafios na trajetória da implementação de um documento-base para a educação formal no Brasil. Anais VIII Jornadas Internacionais de Políticas públicas. São Luís, UFMA.

Shiroma, E.; Campos, R. F.; Garcia, R. M. C. (2005). Decifrar textos para compreender a política; subsídios teórico-metodológicos para análise de documentos. Perspectiva, Florianópolis, 23, 02, 427-466.

Tello, C. G. (2015). La enseñanza de la política educacional e la formación de investigadores en el campo. Entre las matrices históricas y la episteme de época. Revista de Educação Pública, Cuiabá, 34, 55, 125-151.

Tello, C. G., Almeida, M. L. P. (2013). Estudos epistemológicos no campo da pesquisa em política educacional. Campinas: Mercado de Letras.

Teixeira, B. B. (2008). Uma política e vários contextos: os PCN do ensino fundamental. InterSciencePlace, 3, 1-21. 
Teixeira, B. B. (2011). Política curricular e formação de professores: os PCN no projeto Veredas em Minas Gerais. Currículo sem Fronteiras, 11, 36-53.

Data de recebimento: $25 / 08 / 2015$

Data de revisão: 27/09/2015

Data do aceite: $15 / 12 / 2016$ 